\title{
Degradation of Indigo Carmine Using Advanced Oxidation Processes: Synergy Effects and Toxicological Study
}

\section{Elba Ortiz ${ }^{*}$, Violeta Gómez-Chávez¹, Carlos M. Cortés-Romero², Hugo Solís ${ }^{1}$, Rubén Ruiz-Ramos ${ }^{3}$, Sandra Loera-Serna ${ }^{1}$}

${ }^{1}$ Department of Basic Sciences, Universidad Autónoma Metropolitana Azcapotzalco, Mexico City, Mexico

${ }^{2}$ Faculty of Engineering, Universidad Autónoma de Querétaro-Campus Aeropuerto, Queretaro, Mexico

${ }^{3}$ Institute of Forensic Medicine, Universidad Veracruzana, Veracruz, Mexico

Email:^mariaelbaortiz@gmail.com

How to cite this paper: Ortiz, E., GómezChávez, V., Cortés-Romero, C.M., Solís, H., Ruiz-Ramos, R. and Loera-Serna, S. (2016) Degradation of Indigo Carmine Using Advanced Oxidation Processes: Synergy Effects and Toxicological Study. Journal of Environmental Protection, 7, 1693-1706. http://dx.doi.org/10.4236/jep.2016.712137

Received: August 4, 2016

Accepted: November 4, 2016

Published: November 7, 2016

Copyright $\odot 2016$ by authors and Scientific Research Publishing Inc. This work is licensed under the Creative Commons Attribution International License (CC BY 4.0).

http://creativecommons.org/licenses/by/4.0/

\section{(c) (7) Open Access}

\section{Abstract}

The physicochemical degradation of Indigo Carmine (IC) dye in aqueous solution was performed using single and combined Advanced Oxidation Processes (AOP's). Photocatalysis $\left(\mathrm{TiO}_{2}-\mathrm{UV}\right)$, Ozonation $\left(\mathrm{O}_{3}\right)$ and Sonolysis $(\mathrm{SN})$ were tested either in a standalone methodology or by combination of two simultaneous AOP's. The dye conversion was followed by both measurements: 1) color removal determined by UV-VIS spectrometry and 2) organic and inorganic load determined by the chemical oxygen demand (COD). A complete and quick color disappearance of model water waste has been obtained by using combination of non-irradiated AOP's, namely, $\mathrm{O}_{3} / \mathrm{SN}$, which contrasts to the combination of irradiated photocatalysis with $\mathrm{O}_{3}$ or sonolysis. Color removal with simultaneous $\mathrm{TiO}_{2}-\mathrm{UV} / \mathrm{SN}$ reached $77 \%$ while $\mathrm{TiO}_{2}-$ $\mathrm{UV} / \mathrm{O}_{3}$ reached $96 \%$ at similar reaction time. On the other hand, the standalone $\mathrm{O}_{3}$ yielded the highest color removal (94.4\%) in 32 minutes whereas SN reached only $39.2 \%$ in 4 hours. The standalone light irradiated $\mathrm{TiO}_{2}-\mathrm{UV}$ reached $93.3 \%$ color removal in one hour of reaction time. These results indicated that non-irradiated (SN and $\mathrm{O}_{3}$ ) enhance synergistic effects that provoke structural changes in dye molecule without reaching total degradation. This is evidenced from FTIR of residuals from reaction mixture in which it has been observed the presence of organic molecules such as aromatics, sulfonic and amines refractory compounds that are mechanistically possible to be found during IC degradation. Also, toxicity tests (MicroTox ${ }^{\circledR}$ Technique) were performed using commercially available bacteria culture before and after IC degradation for each AOP and their combination. Reduction of aqueous dye concentration decreased the level of toxicity of the treated water which is the main target of the AOP's but the presence of the remaining recalcitrant compounds have also toxic effect. 


\section{Keywords}

Photocatalysis, Ozonation, Sonolysis, Indigo Carmine, Synergy, Toxicological

\section{Introduction}

Textile industry plays an important role the same for domestic as for worldwide economy since many years [1] [2]. Relevance of this industry relies on the overwhelming use of water especially for clothes dyeing such as denim. For instance, $170 \mathrm{l}$ of water are needed for dyeing $1 \mathrm{~kg}$ of jeans denim, which dramatically increases the water pollution.

Indigo Carmine (IC) is the most common chemical dye for this process, which is considered as a refractory molecule (Figure 1) since it is required a rather strong chemical treatment for its elimination from the water waste. The presence of this dye in residuals causes notorious change of water color and smell even in very low concentration. Moreover, if some of this water reaches natural streams it can be toxic for aquatic living entities due to the formation of toxic compounds such as aromatic amines [3] [4]. Emergent water treatments for elimination of organic compounds are the Advanced Oxidation Processes (AOP's) that requires rather soft conditions to convert dye molecule to simple products, which are much less toxic. Within these processes, room temperature and atmospheric pressure can be used because the reactive radical $(\mathrm{OH} \bullet)$ is produced at these conditions. Also, smooth operating conditions lead to reduce by-products that might be difficult to eliminate as well as to avoid organic mud formation [5]-[10].

Several reports show an increasing interest in studying simultaneous AOP's that reduce different pollutant from water waste by synergic effect. In fact, this is a result of coupling two or more processes efficiency in one stage treatment of contaminated water. AOP's consist of a wide group of technologies that have been used with success in water and wastewater treatment over the last decades and involve direct Ozonation, ozone and/or $\mathrm{H}_{2} \mathrm{O}_{2}$ in combination with UV, Fenton, photo-Fenton, semiconductor photocatalysis, electrolysis, sonolysis or ultrasound irradiation, wet air oxidation and even biological treatment, among others [11]-[13].

In the present work, the AOP's were used either in a simple or combined treatment of an aqueous solution of IC that represented the textile water waste. Ozone $\left(\mathrm{O}_{3}\right)$, sonolysis $(\mathrm{SN})$ and photocatalysis $\left(\mathrm{TiO}_{2}-\mathrm{UV}\right)$ were tested in a separated or combined way to reduce or eliminate the dye concentration under similar operating conditions. A

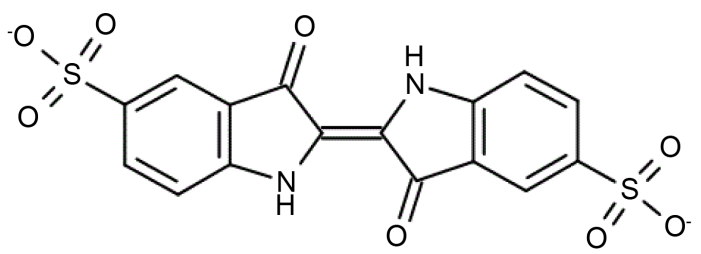

Figure 1. IC molecule structure. 
kinetic reaction model was assumed by means of a simple formalism taking into account the complete set of experiments. The reaction performance was followed by determining the dye concentration using UV-VIS spectrometry and by measuring the amount of organic and inorganic load (chemical demand of oxygen). At the last but not the least, toxicity of reaction residuum was evaluated using a commercially available bio-test $\left(\right.$ MicroTox $\left.^{\oplus}\right)$ based on reduction of bio-luminesce of aquatic bacteria Vibrio fischeri. The principle of this bio-test is the effect that contaminants in water or earth have over living sea bacteria called Vibrio fischeri [14] [15]. Changes in bacteria concentration is sensed by means of natural bio-luminesce that is measured using a special detector. Reduction in bio-luminesce depends on the amount of toxic compounds present in streams. The common expression used for toxicity is the concentration of toxic compound that causes 50\% reduction of the initial bio-luminesce, namely, EC50.

\section{Methodology}

\subsection{Materials and Reagents}

All the experiments were performed using commercially available chemical reagent, except for ozone that was generated in-situ. The indigo carmine disodium disulfonate salt (3,3'-dioxo-2,2'-bis-indolyden-5,5'-disulfonic acid disodium salt, Aldrich) was dissolved in purified (ion-free) water at the same concentration (50 ppm) for the complete set of experiments. The catalyst $\mathrm{TiO}_{2}$ used for the catalytic tests was supplied by SigmaAldrich Chemie GmbH (USA).

\subsection{Experimental Procedures}

The experimental set-up currently used is depicted in Figure 2. The operating conditions

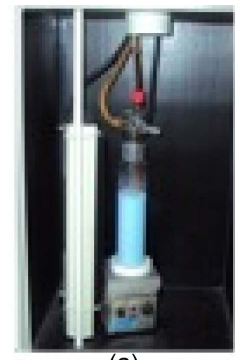

(a)

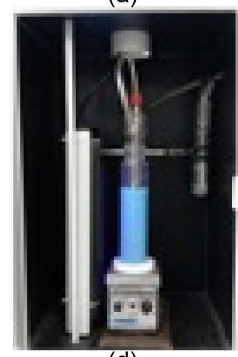

(d)

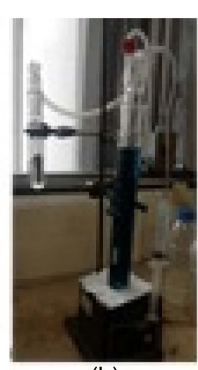

(b)

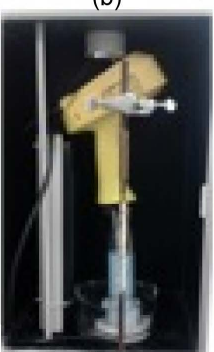

(e)

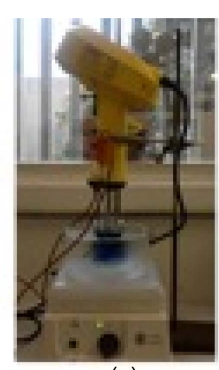

(c)

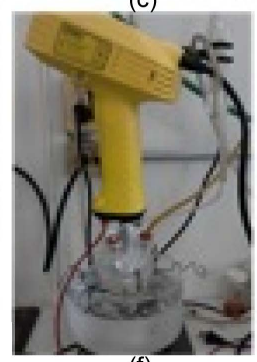

(f)

Figure 2. Experimental set-up for oxidation of IC dye. standalone photocatalysis (a), ozonation (b), sonolysis (c). simultaneous photocatalysis/ozonation (d), photocatalysis/sonolysis (e), and ozonation/sonolysis (f). 
were set at room temperature and atmospheric pressure. The range of $\mathrm{pH}$ was determined by the reaction itself without further external adjustment. The experiments were performed three times for all the operating conditions screening, in order to evaluate the data reproducibility. The following treatments Ozonation $\left(\mathrm{O}_{3}\right)$, Photocatalysis $\left(\mathrm{TiO}_{2}-\mathrm{UV}\right)$ and Sonolysis $(\mathrm{SN})$ were applied standalone, or in combination of irradiated/non-irradiated processes (Photocatalysis-Ozonation $\left(\mathrm{TiO}_{2}-\mathrm{UV} / \mathrm{O}_{3}\right)$ and Photocatalysis-Sonolysis $\left(\mathrm{TiO}_{2}-\mathrm{UV} / \mathrm{SN}\right)$ ) and those of non-irradiated processes (Ozonation/Sonolysis $\left(\mathrm{O}_{3} / \mathrm{SN}\right)$ ) to IC aqueous solution (the model textile wastewater). Color removal by UV-VIS spectrometry and inorganic and organic load by Chemical Oxygen Demand (COD) for all samples was measured. The procedure of this organic load determination was based on complete mineralization through the severe oxidation of organic compounds using a chromic mixture [16] [17]. Finally, residuum of every experiment was dried to obtain solid to perform FTIR analysis. Moreover, a $5 \mathrm{~mL}$ residuum of each experiment was kept to perform toxicity test, as it has been describe in previous section.

\subsubsection{Photocatalytic Treatment $\left(\mathrm{TiO}_{2}-\mathrm{UV}\right)$}

The catalytic reactor was a quartz cell that was treated in a UV chamber that was provided of a dual 254/365 nm UV lamp (Cole-Parmer, 8n watts, $115 \mathrm{~V} / 60 \mathrm{~Hz}$ and $0.16 \mathrm{~A}$ ), see Figure 2(a). The amount of catalyst $\left(\mathrm{TiO}_{2}\right)$ was evaluated by UV-VIS spectrometry within the range of $10-30 \mathrm{mg}$ (difference of $5 \mathrm{mg}$ among experiments) using $10 \mathrm{~mL}$ of dye aqueous solution. Reaction mixture was violently stirred during 10 minutes and centrifuged to separate the catalyst. The amount of the catalyst was set in $30 \mathrm{mg}$ from preliminary results and for the subsequent experiments. It is necessary to stress that the experimental set-up was isolated with black paper to avoid influence of external light that could affect the reaction performance. The performance of our experimental conditions were compared to those literature reported by means of two runs at $254 \mathrm{~nm}$ and $365 \mathrm{~nm}$ [18]. Noteworthy, the best performance of catalytic reaction was obtained using the $365 \mathrm{~nm}$ wavelength and the results are currently reported. Reaction time was set at 60 minutes taking samples every 10 minutes. The total volume of dye solution was 200 $\mathrm{mL}$ in every experiment.

\subsubsection{Ozonation $\left(\mathrm{O}_{3}\right)$}

The ozone Residual Device was used in this series of experiments. Two volumetric oxygen flows ( 0.25 and 0.30 liter per minute) and three voltages $(0.75,2$ and $3 \mathrm{kV})$ were tested for ozone production. The reactor was provided of a gas inlet and purge to avoid pressure increases in the system since an accumulation of gas could occur (see Figure 2(b)). Reaction times were set at 6,12 and 32 minutes for testing with following parameters $0.25 \mathrm{LPM}-3 \mathrm{kV}, 0.3 \mathrm{LPM}-2 \mathrm{kV}$ and $0.3 \mathrm{LPM}-0.75 \mathrm{kV}$, respectively. Sampling was taken every 2 minutes for the first two reaction conditions and every 4 minutes for the latter one.

\subsubsection{Sonolysis (SN)}

Glass reactor was used for this series of experiments. An ultrasound bath Hielscher UP 
$200 \mathrm{Ht}$ was used with frequency setting at $26 \mathrm{kHz}, 240 \mathrm{~V}-60 \mathrm{~Hz}$ and $200 \mathrm{~W}$ atts of power. The experiments were performed using 100\% ultrasound width, see Figure 2(c). Unlike the other two oxidation processes, ultrasound tests were longer and sampling were performed every 40 minutes. Temperature in these experiments was controlled externally by means of ice bath to avoid loss of water and error in dye concentration.

\subsubsection{Photocatalysis/Sonolysis $\left(\mathrm{TiO}_{2}-\mathrm{UV} / \mathrm{SN}\right)$}

The experimental set-up for these experiments was that used for single $\mathrm{TiO}_{2}-\mathrm{UV}$ as it has been described. For the sake of comparison, the operating conditions were set in the same range as that used for single AOP's (see Figure 2(e)). Experiments were performed using UV-light radiation (only $365 \mathrm{~nm}$ wavelength experiment is currently reported) with simultaneous ultrasound treatment. Experimental test was followed during 140 minutes taking samples every 20 minutes.

\subsubsection{Photocatalysis/Ozonation $\left(\mathrm{TiO}_{2}-\mathrm{UV} / \mathrm{O}_{3}\right)$}

The quartz reactor described for photocatalytic section was used for current experiments. Operating conditions were similar to the previous sections but using volumetric ozone flow set in 0.3 liter per minute and $0.75 \mathrm{kV}$ (see Figure 2(d)). Once again, only the results obtained at $365 \mathrm{~nm}$ wavelength are currently reported. Due to the high reaction rate, the reaction time was set to 16 minutes taking samples every 2 minutes.

\subsubsection{Ozonation/Sonolysis $\left(\mathrm{O}_{3} / \mathrm{SN}\right)$}

The glass reactor described for sonolysis section was used for the current experiments. Also, volumetric flow of 0.3 liter per minute and $0.75 \mathrm{kV}$ were set for ozone production (see Figure 2(f)). Also, the high reaction rate under these conditions led to establish 6 minutes as the final reaction time with samples taken every minute.

\subsection{Characterization}

The chemical oxygen demand (COD) was measured by sample digestion and spectrophotometric quantification at $442 \mathrm{~nm}$, using a DR/2400 portable spectrophotometer (HACH Company, Loveland CO USA 80539) after filtrating spin dry the samples. Color removal was measured by a colorimetric method based on an UV/Vis scan using a Cole-Parmer UV-VIS Spectrometer in a quartz cuvette. Toxicity was determined for every experiment by using MicroTox ${ }^{\bowtie}$ technique. These essays are normally used to verify the level of toxic compounds concentration in water or solid waste after treatment. As we explained above, the principle of this bio-test is follows the changes in bacteria concentration by natural bio-luminesce that is measured using a special detector. Reduction in bio-luminesce depends on the amount of toxic compounds present in streams [14] [15].

\section{Results and Discussion}

\subsection{Relationship of Dye Concentration to Spectrometric Response}

The wavelength of visible light was $400-800 \mathrm{~nm}$ while UV region was $200-400 \mathrm{~nm}$. 
Spectrum of a conventional $50 \mathrm{ppm}$ IC concentration is depicted in Figure 3. Quartz cell was used for this analysis. It is worth mentioning that glass cell showed certain interference in sample absorbance at the UV region. According to the UV-VIS spectrum, it can be observed that peaks correspond to structural characteristics of IC. Although it is obvious, it is important to mention that the original blue color of the IC solution has a maximum signal at $610 \mathrm{~nm}$ that corresponds to visible region. Also, the three peaks observed at the UV region correspond to structural features of organic molecule. Peak at $290 \mathrm{~nm}$ is related to amino group. Signal at $250 \mathrm{~nm}$ is attributed to the carbonyl group while that at $205 \mathrm{~nm}$ corresponds to resonance of the aromatic ring.

The linear response of the dye concentration (ppm) to maximal UV-VIS absorbance is confirmed according to Figure 4. Samples of known IC concentration were prepared for the spectrometric calibration curve. The range of dye concentration was from 0 to

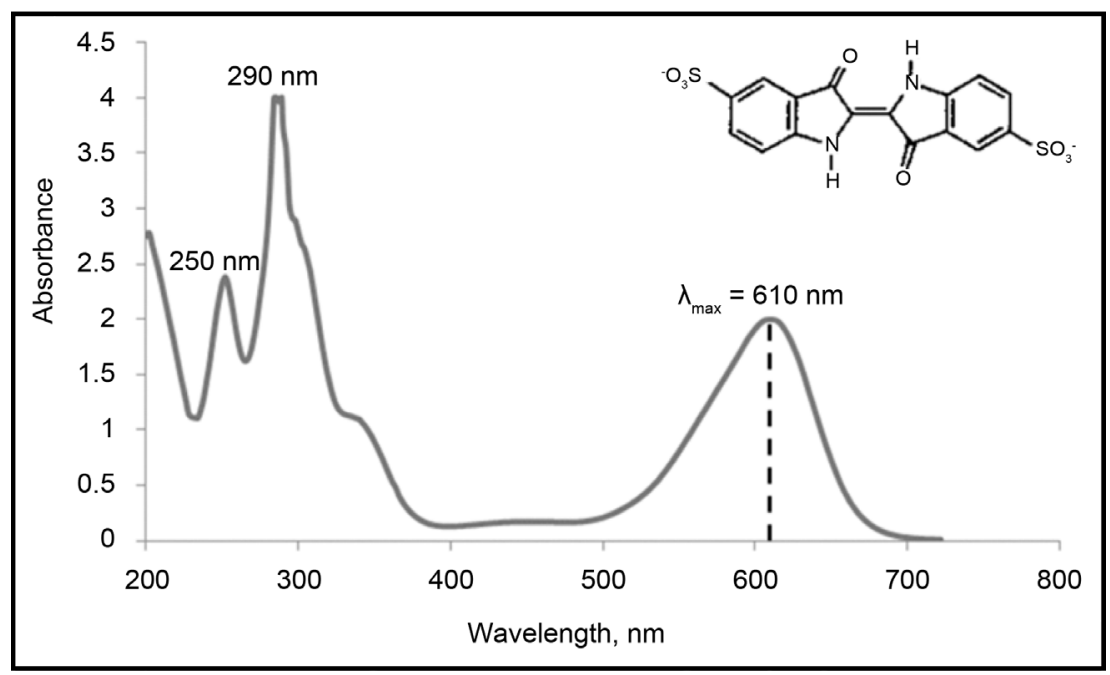

Figure 3. UV-Vis spectrum of IC.

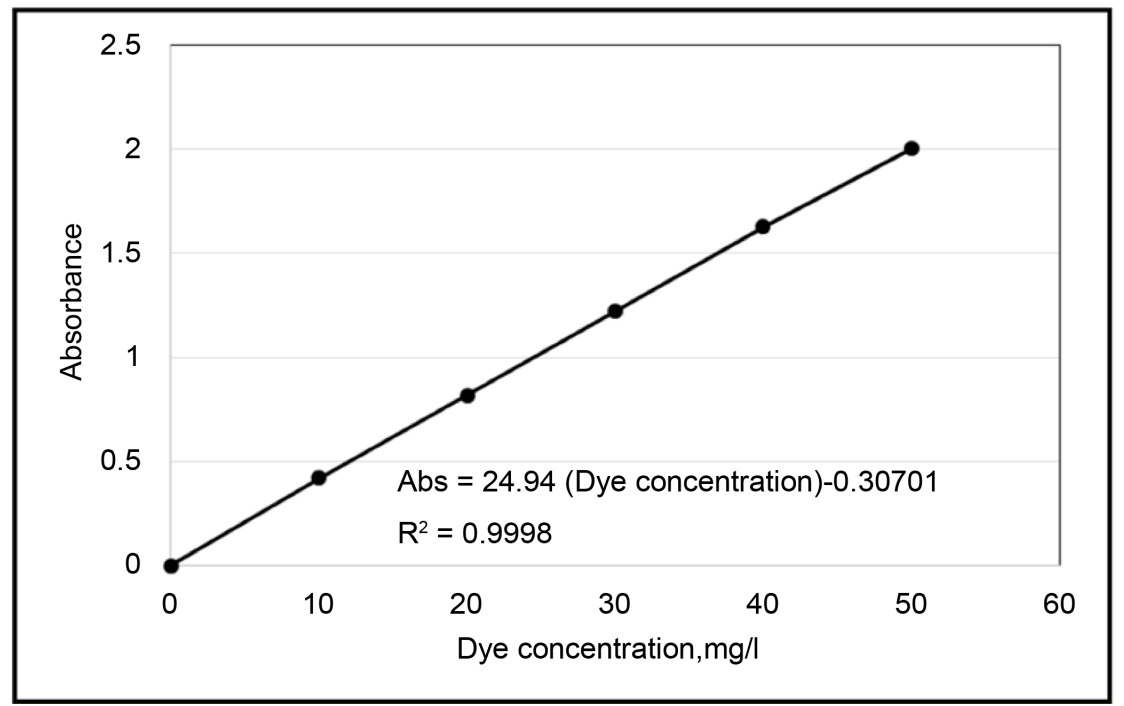

Figure 4. Calibration curve of IC at $\lambda=610 \mathrm{~nm}$. 
$50 \mathrm{ppm}$ since the latter was the initial IC aqueous concentration.

\subsection{Chemical Oxidation Using Standalone Processes}

Figure 5(a) shows the behavior of color disappearance as a function of time for the standalone oxidation process. The color removal occurs faster in the presence of $\mathrm{O}_{3}$ than $\mathrm{TiO}_{2}$-UV irradiated catalytic and $\mathrm{SN}$ treatment. This indicates that treatment with $\mathrm{O}_{3}$ enhances the rate of oxidation almost twice that of $\mathrm{TiO}_{2}-\mathrm{UV}$ and 17 times that from SN.

Table 1 summarized the experimental kinetic results of IC degradation as well as the final dye conversion not only for standalone processes but also for their combination. The $\mathrm{pH}$ was measured at the end of each experiment and it was rather similar for all cases $(4.5$ - 5.7). It is well known that the actual oxidation species are those free oxygen-based radicals $\left(\bullet \mathrm{OH}, \mathrm{HO}_{2} \bullet\right.$, and $\left.\mathrm{O}_{2}^{-} \bullet\right)$ [10], which are generated in situ from water, $\mathrm{O}_{3}$ and $\mathrm{O}_{2}$ and promoted by light irradiation. These species play important role in different reactions towards a complete mineralization of organic molecules. It is relevant, hence, to provide these reactant species to the system to be able decompose as much as possible the dye molecule to low-molecular weight compounds (e.g., small aldehydes, carboxylic acids or small inorganic compounds), $\mathrm{CO}_{2}$, and $\mathrm{H}_{2} \mathrm{O}$, without significant
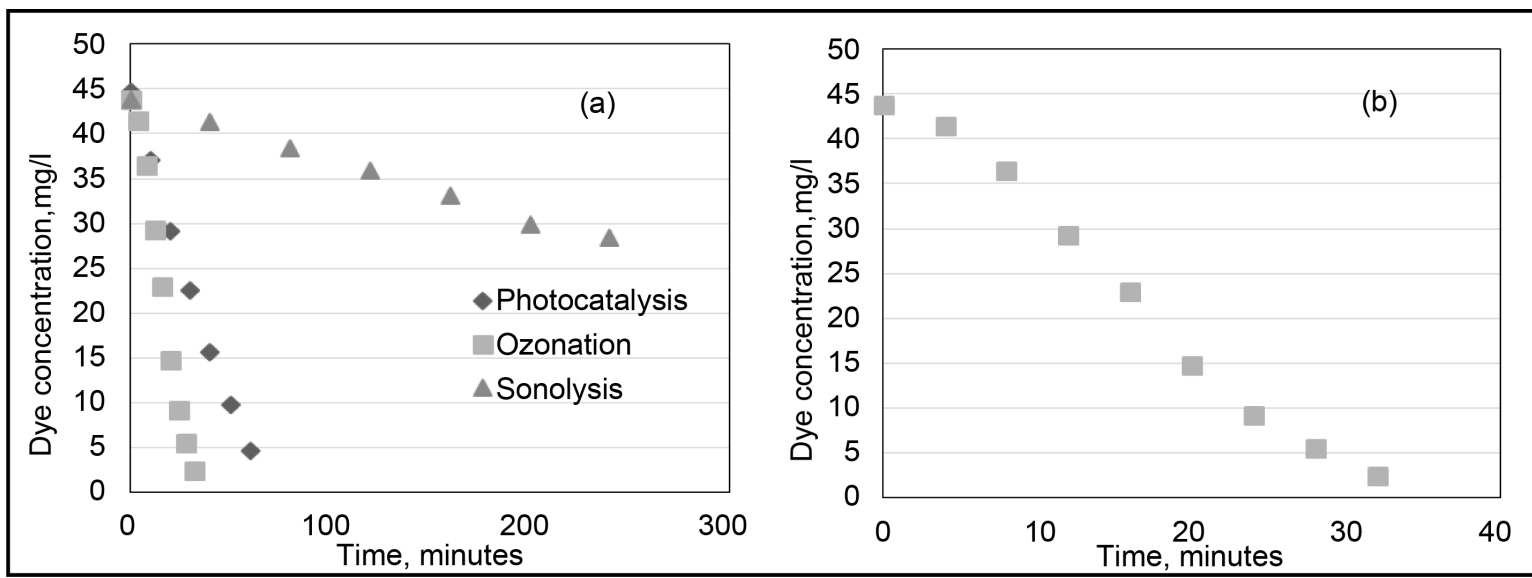

Figure 5. Color removal of indigo carmine aqueous solution using standalone oxidation processes (a) and a closed-up to the ozonation curve (b).

Table 1. Experimental kinetic results of IC degradation with different AOPs.

\begin{tabular}{ccc}
\hline $\mathrm{AOP}$ & Calculated averaged reaction rate, $\times 10^{-6}, \mathrm{~mol} \mathrm{l}^{-1} \mathrm{~min}^{-1}$ & Dye removal, \% \\
\hline $\mathrm{TiO}_{2}-\mathrm{UV}$ & 1.6 & 89.7 \\
$\mathrm{O}_{3}$ & 2.5 & 94.5 \\
$\mathrm{SN}$ & 0.2 & 39.2 \\
$\mathrm{TiO}_{2}-\mathrm{UV} / \mathrm{SN}$ & 0.5 & 77.4 \\
$\mathrm{TiO}_{2}-\mathrm{UV} / \mathrm{O}_{3}$ & 4.8 & 89.5 \\
$\mathrm{O}_{3} / \mathrm{SN}$ & 17.8 & 100.0
\end{tabular}


production of pollutant secondary solids. Discussion relies in the mass transport limitations of both dye and oxidizing molecules, which are present in this type of process. One can control and avoid these limitations by using high-speed stirring and heat. For our results, it is can be evidenced some diffusion limitation for ozonation from the initial reaction rate but it reaches steady state condition quite soon. It can be assumed that a pseudo-equilibrium of ozone dissolution and reactant species formation is reached within the first 5 minutes of treatment, see Figure 5(b). Once these species are generated the subsequent oxidation reaction takes place very fast until almost complete color removal is obtained ( $94.5 \%$ final dye removal). Color removal concerns only elimination of the chromophore group in the dye molecule but the complete mineralization of the molecule is not assured only by the type of process. This is evidenced from the results of the total organic load analyses and the toxicity determination of the residuum from the reaction.

Table 2 shows the percentage of organic load by chemical oxygen demand (COD). The results indicate the amount of remaining organic molecules susceptible to be mineralized. The lower the values of organic load the more complete the dye oxidation due to the treatment. The $\mathrm{O}_{3}$ yielded the lower remaining organic load of the set of standalone processes within a rather short time. According to results, $\mathrm{SN}$ is not that effective as expected for both color removal and organic molecules degradation. This indicates that the oxidizing species are scarcely formed by SN treatment, which means that activation of these molecules is an energy demanding process.

Results of toxicity for the standalone AOP's are related to the degree of bioluminescence observed using the Microtox ${ }^{\oplus}$ biotest. After the 15 minutes treatment of the $\mathrm{Vi}$ brio fischeri bacteria culture with residuum of every experiment, the bio-luminiscence was measured and the result was compared to the blank test that is the $100 \%$ bio-luminiscence value obtained with bacteria alone. According to the results, the products obtained during dye oxidation (intermediates or final mineralization products) show toxic effect for the bacteria. Apparently, the product obtained in SN shows no toxic effect; since the response reached $100 \%$, see Table 2 . So far, it is difficult to know what the reason is for this result since we still have no clues of the chemical structure of any product in each experiment. In this concern, FTIR analyses might help

Table 2. Organic load of dye degradation by standalone and combined AOP's.

\begin{tabular}{cccc}
\hline AOP & \multicolumn{2}{c}{ Time, min Organic load by COD, (\%) } & Toxicity test, \% biochemiluminiscence $^{\mathrm{a}}$ \\
\hline Indigo Carmine, (blank test) $^{2}$ & 0.0 & 100.0 & $100.0^{\mathrm{b}}$ \\
$\mathrm{TiO}_{2}-\mathrm{UV}$ & 60.0 & 35.3 & 51.0 \\
$\mathrm{O}_{3}$ & 32.0 & 17.9 & 70.0 \\
$\mathrm{SN}$ & 240.0 & 80.3 & 100.0 \\
$\mathrm{TiO}_{2}-\mathrm{UV} / \mathrm{SN}$ & 140.0 & 25.6 & 53.0 \\
$\mathrm{TiO}_{2}-\mathrm{UV} / \mathrm{O}_{3}$ & 16.0 & 24.2 & 60.0 \\
$\mathrm{O}_{3} / \mathrm{SN}$ & 6.0 & 26.7 & 74.0 \\
\hline
\end{tabular}

${ }^{a}$ Measured after 15 minutes treatment of Vibrio fischeri bacteria biotest with residuum of each oxidation process. ${ }^{\mathrm{b}} \mathrm{Blank}$ test means that only bacteria is present in the biotest. 
to elucidate the type of functional groups that can relate a chemical structure of oxidation products.

The FTIR spectra of IC dye reagent and the reaction product from each process are depicted in Figure 6. Since the signals obtained from FTIR spectroscopy are caused by substance-specific vibration modes of the molecular structure, they can readily be attributed to functional groups as it is shown in Table 3. There are some similarities among the spectra of the reference dye and those from the residuum of each reaction product.

The FTIR spectra of untreated IC dye showed the specific peaks in fingerprint region $\left(1500-500 \mathrm{~cm}^{-1}\right)$ for the orto-para-disubstituted benzene rings, which is supporting to the peak at $1613 \mathrm{~cm}^{-1}$ for the $\mathrm{C}=\mathrm{C}$ stretching of the benzene ring. A characteristic peak in the range $1100-1000 \mathrm{~cm}^{-1}$ is related to the $\mathrm{S}=\mathrm{O}$ stretch band with the most significant absorbance peak being at $1030 \mathrm{~cm}^{-1}$ and another one in the range $740-690 \mathrm{~cm}^{-1}$ for the C-S stretching vibrations due to sulfur containing functional groups. The observed bands in the region of $3300-3500 \mathrm{~cm}^{-1}$ are due to the $\mathrm{O}-\mathrm{H}$ stretching that can be attributed to water remains. The band assigned to carbonyl bond can also be observed at $\sim 1660 \mathrm{~cm}^{-1}$.

For all the synthesized samples from experiments, the whole set of bands of the molecular skeletal vibrations were shifted, broadened and reduced after oxidation treatment. This result together with those of color removal and toxicity indicate that partial or complete dye molecule degradation has occurred. Perhaps the formation of sulfonates, carbonates, formates, acetates, propionates, benzoates, etc., suggest that the products were undergoing irreversible chemical changes, probably due to concomitant degradation and autoxidation reactions of the products formed during the reductive dye degradation. These results suggest that AOP's easily react with chromophore group but further degradation of intermediates that contain phenyl groups becomes more difficult which leads to toxic and recalcitrant compounds formation. Nevertheless, these intermediate compounds are rather less toxic than IC molecule [10].

\subsection{Chemical Oxidation Using Combined Oxidation Processes: Synergy Effects}

The actual combination of oxidation processes lead to better and more promising experimental results. The trend in color removal is depicted in Figure 7 for the combined AOP's.

Combination of AOP's lead to higher conversions and reaction rates which is evidence of the presence of a synergistic effect between treatments. When ozone is present either in $\mathrm{TiO}_{2}-\mathrm{UV}$ or SN processes, the reaction rate increases significantly, see Table 1 . The combination of $\mathrm{SN}$ and $\mathrm{TiO}_{2}-\mathrm{UV}$, however, is not that good as expected even though the reaction rate is increased three times that obtained with standalone SN. It is worth mentioning that during these experiments, the catalyst was stuck to the reactor walls, which might limit its activity, but allowing the oxidation reaction to take place. The case of $\mathrm{O}_{3}$ is more promising either in the presence of a catalyst or with SN treatment. The $\mathrm{O}_{3}$ treatment enhances $\mathrm{SN}$ reaction rate more than 100 times, which indicates 

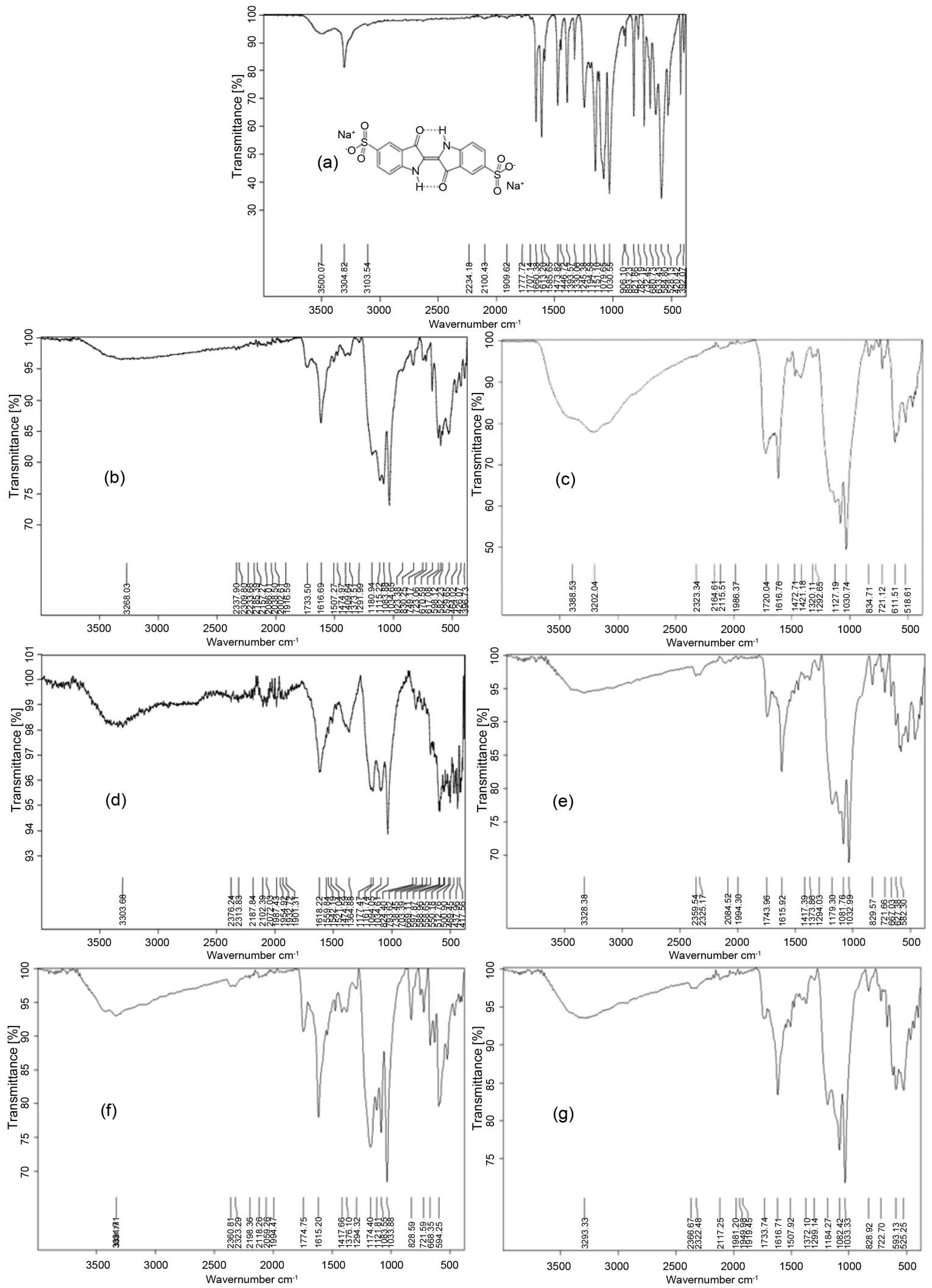

Figure 6. FTIR spectra of IC (a) and reaction product of standalone photocatalysis (b), ozonation (c) and sonolysis (d) as well as combined photocatalysis/ozonation (e), sonolysis/ozonation (f) and sonolysis/photocatalysis ( $\mathrm{g}$ ). 
Table 3. FTIR signals and corresponding functional groups $\left(\mathrm{cm}^{-1}\right)$.

\begin{tabular}{cccccccc}
\hline Functional group & $\mathrm{IC}$ & $\mathrm{TiO}_{2}-\mathrm{UV}$ & $\mathrm{O}_{3}$ & $\mathrm{SN}$ & $\mathrm{TiO}_{2}-\mathrm{UV} / \mathrm{O}_{3}$ & $\mathrm{TiO}_{2}-\mathrm{UV} / \mathrm{SN}$ & $\mathrm{O}_{3} / \mathrm{SN}$ \\
\hline $\mathrm{O}-\mathrm{H}$ & 3500 & - & 3388 & - & - & - & - \\
$>\mathrm{N}-\mathrm{H}$ & 3304 & 3260 & 3202 & 3003 & 3328 & 3293 & 3371 \\
$>\mathrm{C}=\mathrm{O}$ & 1660 & 1733 & 1730 & - & 1743 & 1733 & 1744 \\
$\mathrm{C}=\mathrm{C}$ & 1613 & 1616 & 1616 & 1618 & 1615 & 1616 & 1616 \\
$\mathrm{C}-\mathrm{N}$ & 1151 & 1180 & 1127 & 1177 & 1179 & 1184 & 1174 \\
$\mathrm{~S}=\mathrm{O}$ & 1030 & 1034 & 1031 & 1034 & 1032 & 1032 & 1033 \\
$\mathrm{C}-\mathrm{S}$ & 732 & 749 & 721 & 738 & 721 & 722 & 722 \\
$\mathrm{R}-\mathrm{O}$ & 1245 & 1291 & & 1161 & 1294 & 1299 & 1294 \\
& 1079 & 1084 & 1292 & 1094 & 1081 & 1182 & 1083 \\
\hline
\end{tabular}

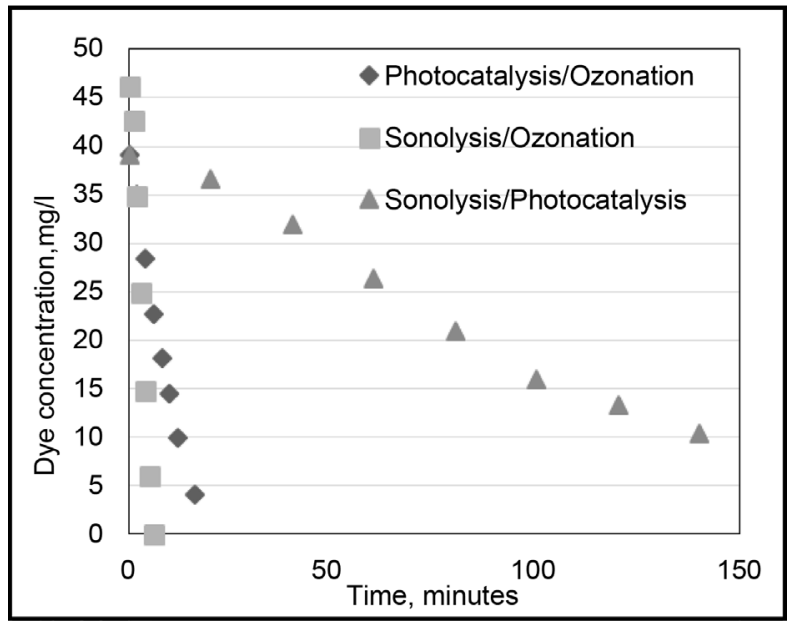

Figure 7. Color removal of aqueous solution of indigo carmine using combined AOP's.

that there must be an activation process on the oxidation species formation, which is promoted by $\mathrm{SN}$. Moreover, $\mathrm{O}_{3} / \mathrm{SN}$ treatment led to complete color removal in a very short time. It has been mentioned that $\mathrm{O}_{3}$ might be affected by transport limitations since ozone gas has to be dissolved in the aqueous reaction media to produce oxidation agent such as the hydroxyl group. By using SN, it seems that ozone solubility is not affected but the production of hydroxyl oxidation agent formation is enhanced. Importantly, the experimental $\mathrm{pH}$ of the $\mathrm{O}_{3} / \mathrm{SN}$ experiment was the lowest (4.5) of the complete set of experimental series. The combination of $\mathrm{TiO}_{2}-\mathrm{UV} / \mathrm{O}_{3}$, however, was moderated although the reaction rate was twice that of standalone $\mathrm{O}_{3}$ and three times that of standalone $\mathrm{TiO}_{2}$-UV.

Concerning the remaining organic load of the combined oxidation processes, similar values were obtained regardless the type of processes combination. This is also confirmed by the toxicity assessment since similar results were also observed. Obviously, the removal of the color is not sufficient to assure there is complete mineralization of the IC molecule and this is the case of the current results. There still some refractory 
intermediate molecules, which require more severe operate conditions to be fully reacted. In this regard, the best results were obtained, again, for the $\mathrm{O}_{3} / \mathrm{SN}$ combination since only $26 \%$ of the initial Vibrio fischeri culture was affected by the reaction product, which was obtained from the 6 minutes experimental test. These recalcitrant compounds are also evidenced from FTIR spectra depicted in Figure 6.

\section{Conclusion}

The degradation of IC by advanced oxidation processes presents some similarities and strong differences depending on the type of process. In general, from our current results, standalone AOP process or the combination of these led to similar refractory intermediates regardless the level of conversion. These compounds showed some toxic effect on life organism. The chemical nature of the reaction product was evidenced by means of FTIR spectra that showed the same fingerprint for all cases of AOP's but different from IC spectrum. The FTIR signals for sulfur, nitrogen and oxygen containing groups were observed as well as phenyl groups, which indicated the presence of carboxylates such as formates, acetates or propionates, as well as sulfates and amine or amide functional groups (isatine, for instances). The ozonation was the best process either being used as standalone or in combination with photocatalytic and sonolysis process. The presence of ozone enhanced formation of those oxidant species such as hydroxyl and peroxydril radical $\left(\bullet \mathrm{OH}, \mathrm{HO}_{2} \bullet\right.$, and $\left.\mathrm{O}_{2}^{-} \bullet\right)$. When ozone was used under ultrasound treatment the best results in conversion and mineralization were obtained (from organic load and toxicity results). This means that ultrasound promotes gas diffusion in the reaction media as well as the formation of the mentioned oxidizing species. The photocatalysis, on the other hand, appeared not to be as effective as it was expected. There was the assumption that $\mathrm{SN}$ provokes cavitation phenomena of the catalyst particle that affected its performance during combined $\mathrm{TiO}_{2}-\mathrm{UV} / \mathrm{SN}$ treatment. Because of this, the catalyst efficiency was limited and synergy between $\mathrm{TiO}_{2}-\mathrm{UV} / \mathrm{SN}$ as well as $\mathrm{TiO}_{2}-\mathrm{UV} / \mathrm{O}_{3}$ never showed up.

\section{Acknowledgements}

The authors would like to thank the financial support given through the CONACyT projects 154,736 and 153,663 . They acknowledge the kind revision and amendments to this contribution done by all the reviewers as well as by some of their colleagues.

\section{References}

[1] Arndt, S.W. and Kierzkowski, H. (2001) Fragmentation: New Production Patterns in the World Economy, OUP, Oxford.

[2] Hunter, J. (2003) Women and the Labour Market in Japan's Industrialising Economy: The Textile Industry before the Pacific War. Psychology Press.

[3] Campos, R., Kandelbauer, A., Robra, K., Cavaco-Paulo, A. and Gübitz, G.M. (2001) Indigo Degradation with Purified Laccases from Trametes hirsuta and Sclerotium rolfsii. Journal of Biotechnology, 89, 131-139. http://dx.doi.org/10.1016/S0168-1656(01)00303-0

[4] Barka, N., Assabbane, A., Nounah, A. and Ichou, Y.A. (2008) Photocatalytic Degradation of 
Indigo Carmine in Aqueous Solution by $\mathrm{TiO}_{2}$-Coated Non-Woven Fibres. Journal of Hazardous Materials, 152, 1054-1059. http://dx.doi.org/10.1016/j.jhazmat.2007.07.080

[5] Rakesh, Ananda, S., Gowda, N.M.M. and Raksha, K.R. (2014) Synthesis of Niobium Doped ZnO Nanoparticles by Electrochemical Method: Characterization, Photodegradation of Indigo Carmine Dye and Antibacterial Study. Advances in Nanoparticles, 3, 133-147. http://dx.doi.org/10.4236/anp.2014.34018

[6] Andreozzi, R., Caprio, V., Insola, A. and Marotta, R. (1999) Advanced Oxidation Processes (AOP) for Water Purification and Recovery. Catalysis Today, 53, 51-59. http://dx.doi.org/10.1016/S0920-5861(99)00102-9

[7] Esplugas, S., Gimenez, J., Contreras, S., Pascual, E. and Rodríguez, M. (2002) Comparison of Different Advanced Oxidation Processes for Phenol Degradation. Water Research, 36, 1034-1042. http://dx.doi.org/10.1016/S0043-1354(01)00301-3

[8] Suzuki, H., Yamagiwa, S., Araki, S. and Yamamoto, H. (2016) Effects of Advanced Oxidation Processes on the Decomposition Properties of Organic Compounds with Different Molecular Structures in Water. Journal of Water Resource and Protection, 8, 823-834. http://dx.doi.org/10.4236/jwarp.2016.89067

[9] Hachem, C., Bocquillon, F., Zahraa, O. and Bouchy, M. (2001) Decolourization of Textile Industry Wastewater by the Photocatalytic Degradation Process. Dyes and Pigments, 49, 117-125. http://dx.doi.org/10.1016/S0143-7208(01)00014-6

[10] Camargo, V., Ortiz, E., Solis, H., Cortes-Romero, C.M., Loera-Serna, S. and Perez, C.J. (2014) Chemical Degradation of Indigo Potassium Tetrasulfonate Dye by Advanced Oxidation Processes. Journal of Environmental Protection, 5, 1342-1351. http://dx.doi.org/10.4236/jep.2014.513128

[11] Comninellis, C. Kapalka, A. Malato, S. Parsons, S.A. Poulios, I. Mantzavinos, D. (2008) Advanced Oxidation Processes for Water Treatment: Advances and Trends for R\&D. Journal of Chemical Technology and Biotechnology, 83, 769-776.

http://dx.doi.org/10.1002/jctb.1873

[12] Horáková, M., Klementová, Š., Kř́ǐ̌, P., Balakrishna, S.K., Špatenka, P., Golovko, O., Hájková, P. and Exnar, P. (2014) The Synergistic Effect of Advanced Oxidation Processes to Eliminate Resistant Chemical Compounds. Surface and Coatings Technology, 241, 154-158. http://dx.doi.org/10.1016/j.surfcoat.2013.10.068

[13] Merayo, N., Hermosilla, D., Blanco, L., Cortijo, L. and Blanco, Á. (2013) Assessing the Application of Advanced Oxidation Processes, and Their Combination with Biological Treatment, to Effluents from Pulp and Paper Industry. Journal of Hazardous Materials, 262, 420-427. http://dx.doi.org/10.1016/j.jhazmat.2013.09.005

[14] Parvez, S., Venkataraman, C. and Mukherji, S. (2006) A Review on Advantages of Implementing Luminescence Inhibition test (Vibrio fischeri) for Acute Toxicity Prediction of Chemicals. Environment International, 32, 265-268.

http://dx.doi.org/10.1016/j.envint.2005.08.022

[15] Backhaus, T., Froehner, K., Altenburger, R. and Grimme, L. (1997) Toxicity Testing with Vibrio fischeri: A Comparison between the Long Term (24 h) and the Short Term (30 min) Bioassay. Chemosphere, 35, 2925-2938. http://dx.doi.org/10.1016/S0045-6535(97)00340-8

[16] Zhang, S., Jiang, D. and Zhao, H. (2006) Development of Chemical Oxygen Demand OnLine Monitoring System Based on a Photoelectrochemical Degradation Principle. Environmental Science \& Technology, 40, 2363-2368. http://dx.doi.org/10.1021/es0520181

[17] Salame, C., Aillerie, M., Papageorgas, P., Pisutpaisal, N. and Sirisukpoca, U. (2014) Technologies and Materials for Renewable Energy, Environment and Sustainability (TMREES14EUMISD)Development of Rapid Chemical Oxygen Demand Analysis Using Ozone as Oxi- 
dizing Agent. Energy Procedia, 50, 711-718.

http://dx.doi.org/10.1016/j.egypro.2014.06.087

[18] Sajan, C.P., Basavalingu, B., Ananda, S. and Byrappa, K. (2011) Comparative Study on the Photodegradation of Indigo Caramine Dye Using Commercial $\mathrm{TiO}_{2}$ and Natural Rutile. Journal of the Geological Society of India, 77, 82-88.

http://dx.doi.org/10.1007/s12594-011-0010-y

Submit or recommend next manuscript to SCIRP and we will provide best service for you:

Accepting pre-submission inquiries through Email, Facebook, LinkedIn, Twitter, etc.

A wide selection of journals (inclusive of 9 subjects, more than 200 journals)

Providing 24-hour high-quality service

User-friendly online submission system

Fair and swift peer-review system

Efficient typesetting and proofreading procedure

Display of the result of downloads and visits, as well as the number of cited articles

Maximum dissemination of your research work

Submit your manuscript at: http://papersubmission.scirp.org/

Or contact jep@scirp.org 